\title{
Moderated Mediation Effect of Feedback Seeking Behavior and Goal Commitment on the relationship between Proactive Personalities and Sales Performance of Insurance Sales Agents in Mombasa, Kenya
}

\author{
Zippy Mukami Njagi, PhD Candidate \\ Dr.Charles Lagat, Senior Lecturer \\ Prof Michael Korir, Senior Lecturer \\ Marketing \& Logistics Department
}

School of Business and Economics, Moi University, Kenya

\section{Doi:10.19044/esj.2019.v15n13p108 URL:http://dx.doi.org/10.19044/esj.2019.v15n13p108}

\begin{abstract}
The purpose of this study was to examine the Moderated Mediation effect of Feedback seeking behavior and Goal Commitment on the indirect relationship between Proactive personalities and Sales performance. The study adapted explanatory research design targeting 448 insurance Sales Agents in Mombasa County, Kenya. Using self-administered questionnaires, reliability test of the research instrument was done by the use of Cronbach's alpha. The Pearson correlation and conditional process analysis, model 4 and model 58 was used to analyze the data and to test each of the hypotheses. The findings of the study confirm a positive effect of Proactive personalities on Sales performance and Goal Commitment. Goal Commitment was also found to positively affect Sales performance. Furthermore, the result confirms the Mediating effect of Goal Commitment on the relationship between Proactive personalities and Sales performance. The study also confirms that Feedback seeking behavior Moderates the relationship between Proactive personalities and Goal Commitment but does not moderate the relationship between Proactive personalities and Sales performance. Lastly the finding confirms that Feedback seeking behavior Moderates the indirect relationship between Proactive personalities and Sales performance via Goal Commitment. Managers and policymakers should formulate policies and strategies which nurture proactive behaviour among sales people by seeking feedback of their performance as they pursue the individual desired and organization's set goals.
\end{abstract}


Keywords: Sales Performance, Proactive personalities, Feedback seeking Behavior and Goal Commitment

\section{INTRODUCTION}

The modern workplace often demands that employees behave proactively. Managers and policymakers have a role to improve their sales processes, strategic plans, ensure proper territory allocation of resources, and institute proper resource planning and compensation programs in their firms. An organization without sales personnel does not meet its objectives and it's therefore necessary to ensure that their performance is excellent. The use of internet by most sales personnel has made it easier for customers to access information and be better informed. The purpose of sales people is to ensure that they transfer information and knowledge about their products to the customers but the main challenge that they face is access to sales which hinders their efforts (Rust et al., (2014). The customers, then, expect the sales people to communicate more on their products and provide details on how their products solve explicit and latent problems. Therefore, sales people must possess knowledge and skills to be able to explain the purpose of their products, and how they solve the customers' problems (Teece et al., (2015). The conversations that take place between customers and the sales people are the ones that help customers to make decisions on whether the products are of importance to them and if they will help them in solving their problems (Odunlami, 2011).This study focuses on Proactive personalities which refers to a sales person's tendency to fix what is wrong, change things and use well planned ideas to solve problems thus increasing levels of performance and meet the set goals. Bakker et al, (2012) argues that employees with proactive personalities use initiative, persevere, and attempt to shape their environment and tend to have a positive impact on job-related outcomes especially in changeable and more dynamic work environments. Goal commitment and goal-performance have a strong relationship in that sales personnel must possess commitment to attain great performance (Sholihin et al., 2011). When positive behavior is experienced in the achievement of a goal, it results to reinforcing behaviors while negative behavior leads to behavior modification. The feedback that the organizations receive help them evaluate the sales personnel's' performance in the work environment. This present study, therefore, investigates the influence of Proactive personalities on Sales performance as Moderated and Mediated by Feedback seeking behavior and Goal Commitment at insurance companies in Kenya. 


\section{LITERATURE REVIEW \\ The Concept of Sales Performance}

According to Woods et al., (2013), sales force performance is the behavior of the work force to ensure a certain goal is met. Also, a successful work force is one that possesses unique activities in their sales to ensure they meet the objectives set. The concept is explained by a seller's level of heterogeneity, consistency and coordination in the activities done bringing out variation in performance Yang et al., (2011). These results were supported by other researchers by categorizing the three into simpler factors of service sold, type of employer, type of customer, vendor requirements as successful activities of a sales person Churchill as cited in Day, (2011). On the other hand Walsh and Lipinski, (2013) indicated that commercial sales, sales mission, technicians and sales of new business as the activities that determine a successful sales person. An organization's goals in accordance with behavior and activities of the employees are the main factors that determine performance Churchill et al., as cited in Day, (2011). The behavior of employees influences how they perform to achieve organizational goals.

\section{Proactive personalities and Sales Performance}

This study adapts Bakker et al., (2012)'s, definition of proactive personalities as the sales person's ability to initiate important change instead of waiting to be told what to do. Crossley et al., (2013) state that, proactive sales people excel more over the course of their careers because they plan carefully and acquire greater understanding of how the politics within the company work. Proactive sales people are asset to their respective companies because they may have higher levels of performance (Kammeyer et al., 2013). Proactive sale's people adjust to their new tasks very quickly because they understand the political surroundings well and make acquaintances more quickly (Zhang et al., 2012). These people are eager to learn and engage in many developmental activities to improve their skills for the purpose of attaining set goals. According to Tolentino et al., (2014) proactive sales people are good at maintaining customer relationships. They put customers at the core of all activities, keeping them informed, making an avenue for complaints and quickly solving their problems and fixing everything that is wrong in order to satisfy them (Grant et al.,2011).

This is also echoed by Chiang and Hsieh (2012) who says that proactive behavior is indirectly linked to effective selling and goal attainment; an assertion underpinned by a logic, which states that in a world of high competition and choice, the passive, reactive seller is unlikely to do as well as his or her more proactive counterpart in achieving performance or set goals by a firm. Research in understanding this construct has been rapidly increasing. Its effects have been studied in varied fields such as career success (Kiazad $e t$ 
al, 2014), job performance through a social capital perspective (Buller and McEvoy, 2012); and charismatic leadership (Oh et al., 2011). Thus employees with proactive personalities use initiative, persevere, and attempt to shape their environment (Bakker et al, 2012) and tend to have a positive impact on jobrelated outcomes especially in changeable and more dynamic work environments which affect goal commitment and an individual's performance. Based on the above discussion the following hypotheses for this study are:

H1 Proactive personalities significantly exert a positive and direct effect on Sales performance.

$\mathrm{H} 2$ Proactive personalities significantly exert a positive and direct effect on Goal commitment

\section{Goal commitment and Sales performance}

Emotions and desire motivates people to put efforts in whatever they do (Locke and Latham, 2013). This therefore shows that most people do whatever they value and desire. Behavior is also affected greatly by goals. There are two types of goals; the first type is ones that are intrinsic in value and employees are motivated to attain them even without a promise of rewards after achievement but others are too discouraging that even with a promise of rewards they become difficult for employees to achieve (Lord et al., 2011).The determination that one puts to achieve a certain goal (Sholihin et al.,2011; Locke \& Latham, 2013) or the will to put more effort to ensure that the goals set are achieved is 'goal commitment '(Zimmerman, 2011; Zhang et al., 2012. Schunk, and Zimmerman 2012) noted that when the management makes a move of involving the employees in setting of goals, they are more motivated to attain them as they feel a sense of obligation which leads to commitment, thus increasing sales performance. Studies have shown that goal-setting has a positive effect on performance as a specific high goal affects choice, effort and persistence. In other words, goal setting increases a person's focus on what is to be accomplished, hence increase in performance. Commitment to a specific high goal also leads to persistence until the goal is achieved (Armstrong and Taylor, 2014; Kruglanski et al., 2018).

Based on the above discussion, the following hypotheses for this study are: H3 Goal commitment significantly exerts a positive and direct effect on Sales performance

H4 Goal commitment significantly mediates the relationship between Proactive personalities and Sales performance.

\section{Feedback Seeking Behavior and Sales Performance}

Feedback-seeking is a process that comprises of three stages: motivation, cognitive processing, and behavior (De Stobbeleir et al., 2011). In the motivation stage, an individual develops a need or desire for feedback. 
This need or desire creates an expected benefit for seeking feedback which motivates the person to engage in the behavior. For example, a person may be motivated to seek feedback in order to improve his or her work which influences performance of the individual (Dahling et al., 2015; Harrison et al., 2015). Alternatively, a person may be motivated to seek feedback in order to get his or her supervisor to release some early criticism so his or her performance appraisal will be less negative (Bernardin and Wiatrowski, 2013; Bednall et al., 2014). Hence, feedback seeking behavior affects goal commitment of an individual and his/her performance.

Based on the above discussions, the following hypotheses for this study are:

H5 Feedback seeking behavior significantly moderates the relationship between Proactive personalities and Sales performance

H6 Feedback seeking behavior significantly moderates the relationship between Goal commitment and Sales performance

H7 Feedback seeking behavior significantly moderates the indirect relationship between Proactive personalities and Sales performance via Goal commitment

\section{Figure 1 Conceptual Model}

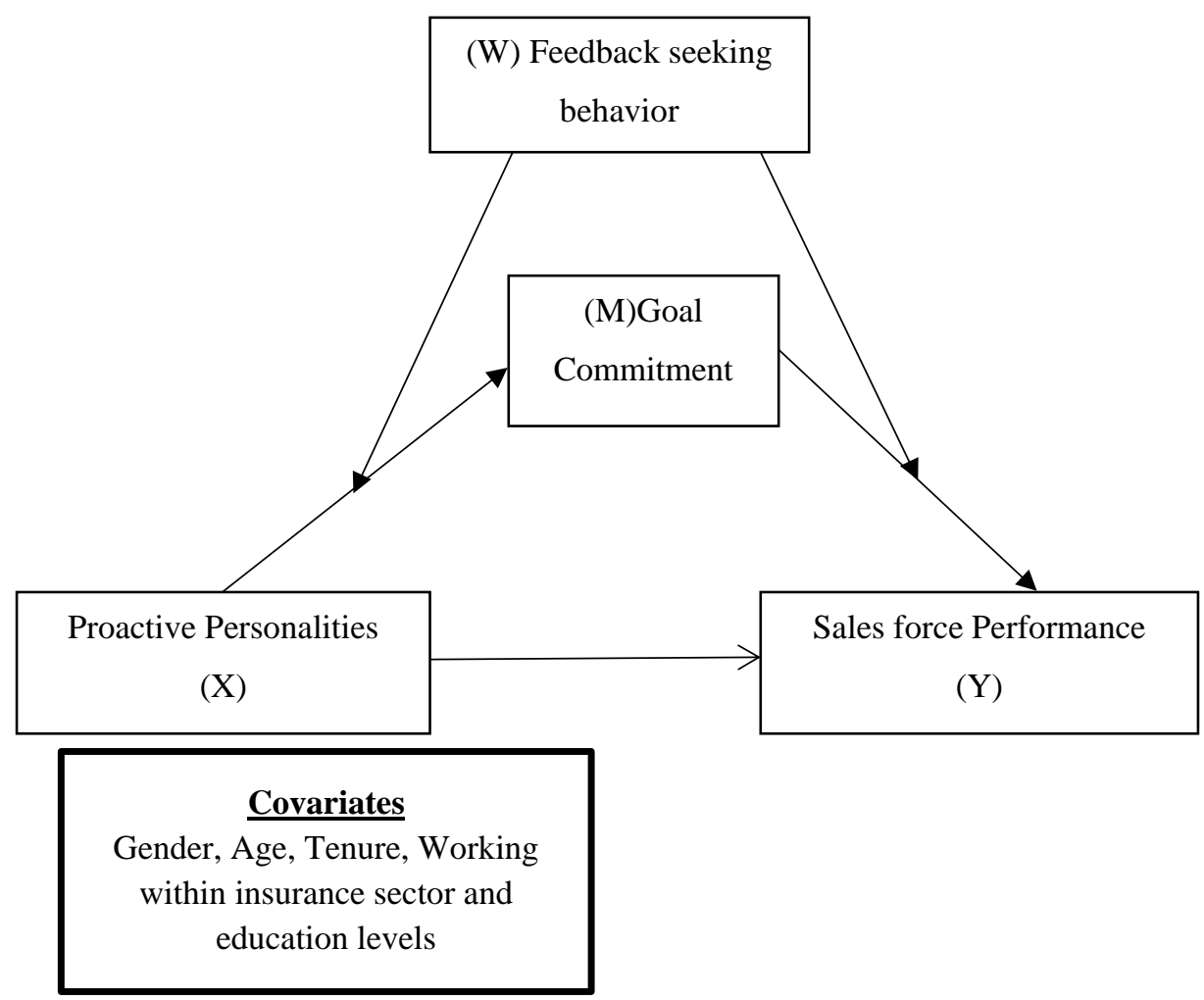

Source: Adopted from Hayes (2013) 
Where:

$\mathrm{X}$ is the Independent variable (Proactive Personality)

$\mathrm{Y}$ is the dependent Variable (Sales Performance)

$\mathrm{W}$ is the Moderator (Feedback Seeking behavior)

$\mathrm{M}$ is the Mediator (Goal commitment)

\section{RESEARCH METHODOLOGY}

\section{Research Philosophy and Research Design of the Study}

This study was approached from a positivism philosophy perspective in which the researcher and the subjects are independent and cannot influence each other or the outcome of the study. In this case, the researcher upholds objectivity by remaining neutral to prevent values and biasness from influencing outcome of the study (Martin and Field 2010). And scientific research approaches are applied from sampling, analysis and interpretation of the results. Explanatory research design was adopted as the study seeks to establish a causal relationship between variables under investigation.

\section{Target Population and Study Area}

This study was conducted in Mombasa, Kenya and the target populations were all authorized sales agents working in all insurance companies with branches in Mombasa Kenya as at May 2017. According to the Association of Kenya Insurers (AKI), there are 68 insurance firms in Kenya (AKI, 2017) out of which 39 of them are in Mombasa with over a thousand sales agents.

\section{Sampling Design and Sample Size}

The population was divided into thirty nine strata reflecting the representation of all the insurance companies with branches in Mombasa. Since the study population was over 1000, it adopted the Cochran's formula (1977) and recommended by Fisher et al., (1991) to obtain the desired sample size.

$$
n=\frac{z^{2} p q}{d^{2}}
$$

1000)

where: $\mathrm{n}=$ the desired sample size (where population is greater than

$\mathrm{z}=$ the standard normal deviate, usually set at 1.96 (or more simply at 2.0), which corresponds to the 95 percent confidence level.

$\mathrm{p}=$ the proportion in the target population estimated to have a particular characteristic.

$\mathrm{q}=1.0-\mathrm{p}, \mathrm{d}=$ degree of accuracy desired, usually set at .05 or occasionally at .02

The sample size was 399 . 
Following the suggestion by Comfrey and Lee (1992) that a sample size of 50-100 is considered very poor; 100-200 very poor; 300-400 good; 400-500 very good, and over 1000-excellent, and based on an assumption of a response rate of previous research (Salkind, 2010) the sample size was increased by $25 \%$ and calculated as $399 * .255=101+399=500$. This large sample allowed for a reasonable and an accurate interpretation of the results.

\section{Measurement of Variables}

Sales performance was measured by using subjective questions rather than objective questions asking participants to rate on a five-point scale from their job performance as indicated by their last formal performance evaluation with items adopted from Ma et al.,(2013), with few modifications to suit the current study. Goal commitment from Klein et al., (2011) and Feedback seeking behavior items from Marlowe- Crowne Social Desirability scale (Crowne and Marlowe, 1960). Proactive personality was measured from direct reports provided self-ratings of their own proactive personality using Seibert, Crant, and Kraimer's (1999) 10-item proactive personality scale. Sample items include 'If I see something I don't like, I fix it' and 'I love being a champion for my ideas, even against others' opposition'. Responses were made using a 5-point Likert scale ( 1 = strongly disagree; 5 = strongly agree).

\section{ANALYSIS AND FINDINGS}

The data contained responses from authorized sales agents working in all insurance companies with branches in Mombasa Kenya. 500 Selfadministered questionnaires were distributed to the respondents out of which, 460 were returned indicating a response rate of $92 \%$. However only 448 questionnaires were used as 12 of them were not properly filled out, hence excluded from the final analysis. This response rate, therefore, shows a good representation of the study population as it was above the adequate $50 \%$ (Mendenhall et al., 2003).

\section{Descriptive Statistics for the Constructs}

Goal commitment showed the highest mean of (4.6) and a standard deviation of (.56) which was followed by Proactive personalities with a mean of (4.3) and a standard deviation of (.66), Feedback seeking behavior construct with a mean of 4.0 and a standard deviation of .73 and Sales performance with a mean of 3.9 and a standard deviation of .65 .

\section{Scale Reliability of the Instruments}

According to Bryman and Bell, (2007) reliability is whether the concept and the result are reliable and if the study can be replicated with the same result. Nunnally (1978) suggests that a suggests that a Cronbach's alpha 
greater than 0.9 indicates high reliability, 0.7 medium reliability, less than 0.5 reveals low reliability and thus the item should be rejected. All items scored higher than 0.5 as required.

\section{Correlation Analysis}

Pearson correlation analysis was done to examine the relationship between the variables. The findings showed the associated pairs of Sales performance with all the variables were significant at 0.01 levels. Based on the results, the correlation between Sales performance and Proactive personalities was the strongest with $r=0.49, p<0.01$. This was followed by Sales performance relationship with Feedback seeking behavior and Goal commitment with $\mathrm{r}=0.196$ and 0.193 respectively $(\mathrm{p}<0.01)$.

\section{Exploratory Factor Analysis of the Variables}

To examine construct validity, 19 items were examined. The KaiserMeyer-Olkin (KMO) had a measure of 0.84 (Table 4.6a) which is above the threshold of 0.5 (Fisher, 2005). The Bartlett's test was significant in this study with a chi-square of 2104.51 ( $\mathrm{p}$-value $<0.00$ ). Therefore, with KMO value of .84 and significance of Bartlett's statistic confirm the appropriateness of the factor analysis for the data set. Table 4.6(b) shows the factor loading for each item for all the variables, Sales performance, Proactive personalities, Goal commitment and Feedback seeking behavior all are sorted by size. Any item that fails to meet the criteria of having a factor loading value of greater than 0.5 and does not load on only one factor was to be dropped from the study (Liao et al., 2007). The Eigen value for each factor is greater than 1.0 (4.72, $2.33,1.53$ and 1.10 which implies that each factor can explain more variance than a single variable. The cumulative percentage of variance explained by the four factors is 50.91 per cent. In other words, more than $51 \%$ of the common variance shared by the 19 items can be accounted or explained by these four factors. Based on these results, the construct validity is established.

Table 4.6 (a) KMO and Bartlett's Test

\begin{tabular}{|l|l|l|l|l|l|}
\hline Component & \multicolumn{2}{|l|}{$\begin{array}{l}\text { Rotation } \\
\text { Sums }\end{array}$} & \multicolumn{2}{|l|}{ Squared Loadings } & .842 \\
\cline { 1 - 4 } & $\begin{array}{l}\text { Eigen } \\
\text { Values }\end{array}$ & $\begin{array}{l}\text { \% of } \\
\text { Variance }\end{array}$ & $\begin{array}{l}\text { Cumulative } \\
\text { percentage }\end{array}$ & $\begin{array}{c}\text { Approx. } \\
\text { Chi-Square }\end{array}$ & 2104.508 \\
\hline 1 & 3.514 & 18.496 & 18.496 & $\begin{array}{c}\text { Bartlett's } \\
\text { Test of } \\
\text { Sphericity } \\
\text { df }\end{array}$ & 171 \\
2 & & & & & \\
3 & 2.539 & 13.361 & 31.857 & & \\
4 & 1.927 & 10.142 & 42.000 & sig & .000 \\
\hline
\end{tabular}


Table 4.6 (b) Summary of the Principal Component Analyses of the Variables

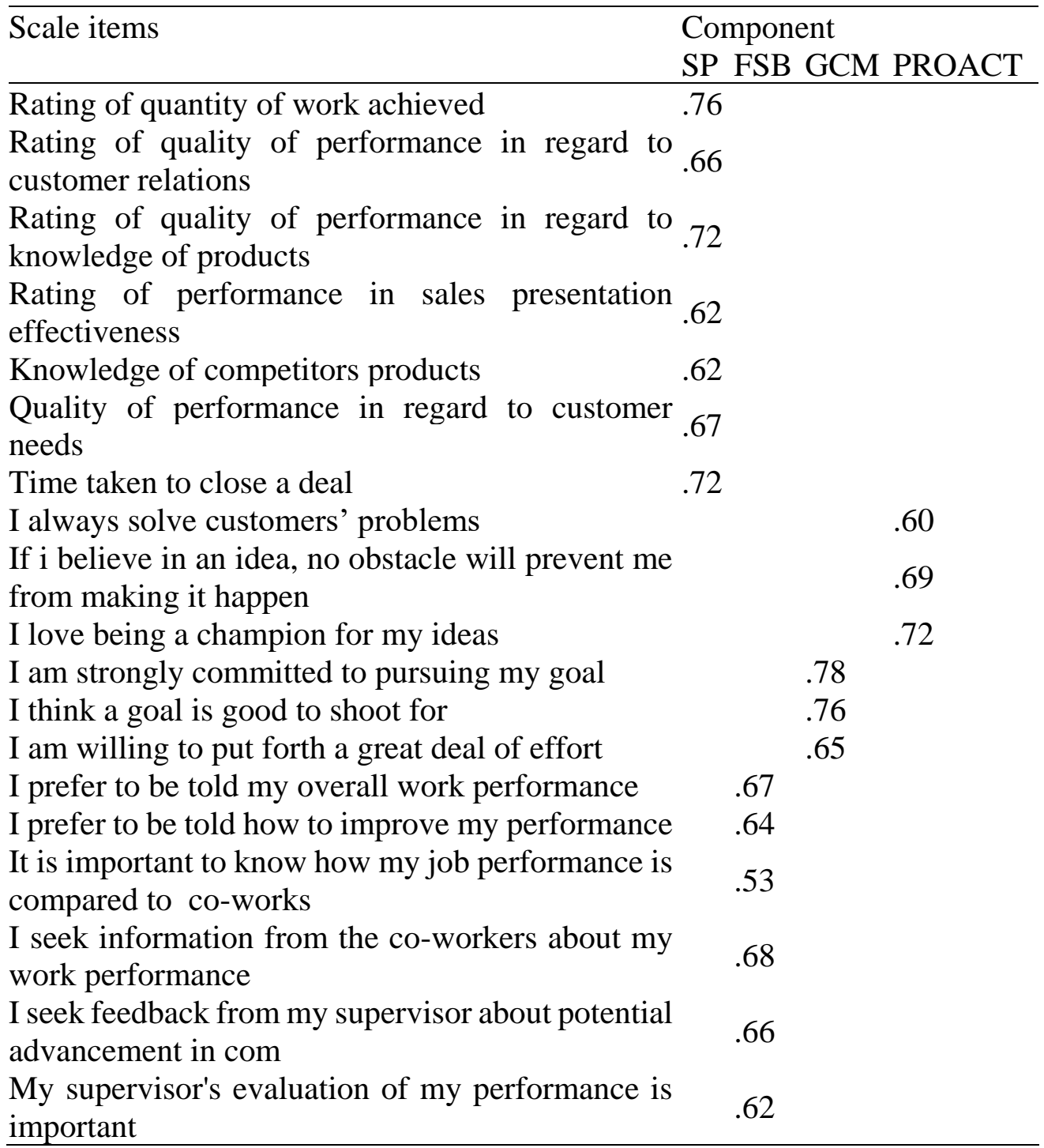

\section{Hypotheses Testing}

The aim of this study was a twofold, to examine whether Goal commitment would mediate the relationship between Proactive personality and Sales performance and lastly to examine whether the indirect relationship between proactive personality through Goal commitment would be moderated by Feedback seeking behavior. Figure 1 illustrates the conceptual model which was also used to construct the hypotheses for the study. Proactive personality was adopted as independent variable in this study, Goal commitment as the mediator and Feedback seeking behavior as the moderator. 
The study examined whether the mediation process was moderated by Feedback seeking behavior. According to Hayes, (2013), moderated mediation is used to determine whether the magnitude of a mediation effect is conditional on the value of a moderator. The bootstrapping method was used to test for the significance of the effects so as to obtain robust standard errors for parameter estimation (Hayes, 2013). The bootstrapping method produced 95\% bias-corrected confidence intervals of these effects from 5000 resamples of the data. Confidence intervals that do not contain zero indicate effects that are significant at $\alpha=05$. In each model, we controlled for relevant covariates namely, gender, age, tenure, working within the insurance sector and education levels and results from both models indicates that none of the covariates was significant. Hypotheses $\left(\mathrm{H}_{1}\right)$ postulated that Proactive personality exerts a significant and direct effect on Sales Performance. Results from table 4.7 (a) model 2 indicates that Proactive personalities had a $\beta=0.28$, $\mathrm{SE}=0.04, \mathrm{t}=6.27$ and $\mathrm{p}=0.00$. Since the $p$-value $<.05$, this hypothesis is supported. The second hypothesis $\left(\mathrm{H}_{2}\right)$ stated that Proactive personality exerts a significantly and direct effect on Goal commitment. The findings from the study on table 4.7 (a) model 1, reveals that Proactive personalities has a $\beta=-$ $0.23, \mathrm{SE}=0.04, \mathrm{t}=5.60$ and $\mathrm{p}=0.00$. Since the $p$-value $<.05$, this hypothesis is also supported. Hypothesis $\left(\mathrm{H}_{3}\right)$ stated that Goal commitment exerts a significant and direct effect on Sales performance. Results from the regression analysis shown on table 4.7(a) model 2 shows that Goal commitment effect on Sales performance had a $\beta=0.20, \mathrm{SE}=0.05, \mathrm{t}=3.70$ and $\mathrm{p}=0.00$. Since $p$ value $<.05$, this hypothesis is supported. Hypothesis $\left(\mathrm{H}_{4}\right)$ postulated that Goal commitment significantly mediates the relationship between Proactive personalities and Sales Performance. Using Hayes model 4, the direct effect of Proactive Personalities on Goal Commitment was significant at a $\beta=0.31$, $\mathrm{SE}=0.04, \mathrm{t}=-8.10$ with $\mathrm{p}=0.00, \mathrm{LLCI}=0.23 \mathrm{ULCI}=0.38$ and direct effect of Proactive Personality on Sales Performance was $\beta=0.29, \mathrm{SE}=0.04, \mathrm{t}=6.71$ with $\mathrm{p}=0.00, \mathrm{LLCI}=0.20 \mathrm{ULCI}=0.37$. Direct effect(s) of Goal Commitment on Sales Performance was significant at $\beta=0.21$ Hayes, (2013) formula was used to test for the Indirect effect of $X$ on $Y$ through $M i=a i$ bi $(\mathrm{ai}=0.31$, $\mathrm{bi}=0.21)(\mathrm{a} \times \mathrm{b})=0.31 \times 0.21=0.07$. The findings on table 4.25 model 2 shows that there is existence of a mediation effect of Goal commitment on the relationship between Proactive personalities and Sales performance with LLCI 0.03 and ULCI 0.11 , therefore the hypothesis was rejected and conclusion was that Goal commitment mediates the relationship between Proactive personalities and Sales Performance. Hypothesis (H5) stated that Feedback Seeking behavior moderates the relationship between Proactive personalities and Goal commitment. Results from table 4.7(a) model 1 indicates the interaction between this variables with a $\beta=-.11, \mathrm{SE}=.04, \mathrm{t}=-$ 
2.85 with $p=.00$, LLCI $=-.18$ ULCI $=-.03$. Since the $p$-value $<.05$ and both LLCI and ULCI have the same negative sign, this hypothesis is supported.

Hypothesis $\left(\mathrm{H}_{6}\right)$ stated that Feedback seeking behavior significantly moderates the relationship between Goal commitment and Sales performance. Results on table 4.7(a), model 2, shows the interaction of Feedback Seeking behavior on the relationship between Goal commitment and Sales Performance. Results shows $\beta=-.01 \mathrm{SE}=.05, \mathrm{t}=-.16$ and $\mathrm{p}=.88$. Since the $p$ value $>.05$, this hypothesis is not supported. Hypothesis $\left(\mathrm{H}_{7}\right)$ postulated that Feedback seeking behavior would moderate the indirect relationship between Self-Efficacy and Sales performance via Goal commitment. To test the moderated mediation hypothesis, the study estimated parameters for two regression models with PROCESS macro (Model 58) by Hayes (2013). Table 4.7(a) indicates the results of the estimates of the moderating effect of Feedback seeking behavior, that is, the relationship between Proactive personalities and Goal commitment (Model 1) and the relationship between Proactive personalities and Sales performance (Model 2). The specifications of the two models were summarized in Table 4.7(a). According to Hayes, (2013), the moderated mediation would be established if one or both of the two patterns existed: (a) the path between Self-efficacy and Goal commitment is moderated by feedback seeking behavior, and/or (b) the path between Goal commitment and Sales performance is moderated by feedback seeking behavior. As indicated in Table 4.7(a), Model 1 reveals that there was a significant direct effect of Proactive personalities on Goal commitment, $\beta=$ $.23, p$-value $<.05$, and this effect is moderated by feedback seeking behavior, $\beta=-.11, \mathrm{p}-\mathrm{v}=.00, \mathrm{LLC} 1=-.18, \mathrm{ULC} 1=-.03$. Model 2 reveals that the effect of Proactive personalities on Sales performance was significant, $\beta=.28, p=.00$, but this effect was not moderated by feedback seeking behavior, $\beta=-.01, p$ value $=.88, \mathrm{LLC} 1=-.10, \mathrm{ULC} 1=.08$. Since $\mathrm{p}$ value $>0.5$, the study confirms only the first stage moderated mediation indicated in model 1.The study further confirms the bias-corrected percentile bootstrap results of the indirect effect of Proactive personalities on Sales performance via Goal commitment being moderated by Feedback seeking behavior, with the index of moderated mediation indicating $\beta=.05, \mathrm{SE}=.02,95 \% \mathrm{CI}=[.02, .08]$ (Table 4.7b). For low Feedback seeking behavior, Proactive personalities had a high influence on Sales performance through increased Goal commitment, $\beta=-.73 \mathrm{SE}=.06$, $95 \% \mathrm{CI}=[.02, .11]$, we therefore conclude that the indirect effect was much stronger for lower feedback seeking behavior, $95 \% \mathrm{CI}=[.02, .11]$ than in the higher feedback seeking behavior, $\mathrm{SE}=.03,95 \% \mathrm{CI}=[.00, .08] . \mathrm{H}_{7}$ is $\mathrm{t}$ supported. 
Table 4.7 (a) Regression Results for Moderated Mediation of Feedback seeking behavior and Goal commitment on Proactive Personality and Sales performance

\begin{tabular}{|c|c|c|c|c|c|c|}
\hline Predictors & Model 1 & (Goal & Commitment) & Model 2 & (Sales & Performance) \\
\hline & $\begin{array}{l}\text { Beta } \\
\text { Coeff }\end{array}$ & $\begin{array}{l}\text { t- } \\
\text { values }\end{array}$ & P-value & $\begin{array}{l}\text { Beta } \\
\text { Coeff }\end{array}$ & $\begin{array}{l}\text { t- } \\
\text { values }\end{array}$ & P-value \\
\hline Constant & -.15 & -1.30 & .19 & 3.77 & 30.15 & .00 \\
\hline Gender & .09 & 1.87 & .06 & -.06 & -1.04 & .30 \\
\hline Age & .00 & .16 & .87 & -.04 & -1.44 & .15 \\
\hline Tenure & -.03 & -.70 & .48 & .06 & 1.55 & .12 \\
\hline $\begin{array}{l}\text { Wkg within } \\
\text { Ins. }\end{array}$ & .01 & .36 & .72 & .06 & 1.59 & .11 \\
\hline Education & .02 & .67 & .50 & .03 & 1.12 & .26 \\
\hline Proactive & .23 & 5.60 & .00 & .28 & 6.27 & .00 \\
\hline $\begin{array}{l}\text { Goal } \\
\text { commitment }\end{array}$ & - & - & - & .31 & -8.10 & .00 \\
\hline $\begin{array}{l}\text { Proactive } * \\
\text { Feedbacks }\end{array}$ & -.11 & -2.85 & .00 & - & - & - \\
\hline $\begin{array}{l}\text { Goal com* } \\
\text { Feedbacks }\end{array}$ & - & - & - & -.01 & -.16 & .88 \\
\hline$R^{2}$ & .1857 & & & .2275 & & \\
\hline
\end{tabular}

Table 4.7 (b) Conditional Indirect Effects of Proactive on Sales performances: (Mediator)

\begin{tabular}{llllll}
\hline & Feedback & Beta coef. & SE & BootLLC1 & BootULC1 \\
\hline $\begin{array}{l}\text { Goal } \\
\text { Commit }\end{array}$ & -.73 & .06 & .02 & .02 & .11 \\
$\begin{array}{l}\text { Goal } \\
\text { Commit }\end{array}$ & .00 & .05 & .02 & .02 & .09 \\
$\begin{array}{l}\text { Goal } \\
\text { Commit }\end{array}$ & .73 & .03 & .02 & .00 & .08 \\
\hline
\end{tabular}

\section{DISCUSSIONS AND CONCLUSION}

The main objective of this study was to assess the Moderated mediation effect of feedback seeking behavior and Goal Commitment on the indirect relationship between Proactive personalities and Sales performance. The research study adopted Model 4 to test for mediation effects and model 58 of Hayes's (2013) PROCESS macro to perform and analyze the moderated mediation effect, hence determine whether the magnitude of a mediation effect is conditional on the value of a moderator. The study used bootstrapping method to test for the significance of the effects so as to obtain robust standard errors for parameter estimation (Hayes, 2013). Confidence intervals that do not contain zero indicate effects that are significant at $\alpha=05$. The findings on $\mathrm{H}_{1}$ is in line with Crant, (2000), Bakker et al., (2012), Thompson (2005) and Mallin et al, (2014) who argues that Individuals with proactive personalities are motivated to engage in positive extra-role behaviors such as identifying 
improvement opportunities and challenging the status quo, and more specific behaviors such as innovation and career management which leads to higher Sales performance. Findings on $\mathrm{H}_{2}$, are supported by Klein et al.,(2012), who states that Goal Commitment is associated with persistence and may therefore lead people who have (proactive) the most ambitious goals to persist in attaining them despite of all the challenges. $\mathrm{On}_{3}$, the finding is in line with prior studies done by Locke and Latham (1984) and Asmus et al., (2015). In their study on the impact of goal-setting on worker performance, it became clear that their finding suggests that goal- setting and commitment improves task performance which leads to higher output quantity. Findings on H4, This is a new finding in literature; hence a contribution to knowledge as most of the previous studies like Lau (2012), tested the impact of Personality Traits and Goal Commitment on Employees' Job Satisfaction, Mehta et al., (2008), did a research on Team Goal Orientation and Team Performance: The Mediating Role of Team Planning, Theodorakis, (1996), carried out a study on "The influence of goals, commitment, self-efficacy and self-satisfaction on motor performance". But there is no evidence from the literature of any research done on the mediating effect of Goal commitment on the relationship between proactive personalities and sales performance. Findings on H5, This is a new finding as it adds some new understanding to the literature in Proactive personalities, Goal commitment, Feedback seeking behavior, Sales performance and their interrelationships which influence the development of the sales and marketing context. Hypothesis H6 postulates that Feedback Seeking behavior moderates the relationship between Goal commitment and Sales performance. Despite of the importance of these variables in any marketing set up and their direct relationships, the study shows nonexistence of the moderating in their interaction hence the hypothesis is not supported. Hypothesis $\mathrm{H} 7$ stated that Feedback seeking behavior moderates the indirect relationship between Proactive personalities and Sales performance via Goal commitment. The finding reveals the existence of a moderated mediated relationship of Feedback seeking behavior on the indirect relationship between the variables. This is further confirmed by bias-corrected percentile bootstrap results of the indirect effect of Proactive personalities on Sales performance via Goal commitment as moderated by Feedback seeking behavior. The study provides new findings in the literature that, when there is low Feedback seeking behavior in an organization, Proactive personality tends to have a high impact on Sales performance through increased Goal commitment, This is proved by the result indicating that the indirect effect was much stronger for lower feedback seeking behavior, than in the higher feedback seeking behavior. 


\section{Conclusion of the Study}

This study addressed a gap in the literature by examining the Moderated mediation effect of Feedback seeking behavior and Goal Commitment on the indirect relationship between Proactive personalities and Sales performance. The findings of the study confirm a positive relationship of Proactive personalities on Sales performance, Proactive personalities on Goal Commitment, Goal commitment on Sales Performance. The study also confirms the moderation effect of Feedback Seeking Behavior on the relationship between Proactive personalities and Goal commitment. Furthermore, the study confirms the Mediating effect of Goal commitment on the relationship between Proactive personalities and Sales Performance. Lastly the study confirms that Feedback Seeking Behavior moderates the indirect relationship between Proactive and Sales Performance via Goal Commitment.

\section{Theoretical Implication of the Study}

This study provides new knowledge that Goal commitment mediates the relationship between Proactive personalities and Sales Performance and that Feedback Seeking Behavior moderates the relationship between and Proactive personalities and Goal commitment. Finally the results reveal that Feedback Seeking Behavior moderates the indirect relationship between Proactive and Sales Performance via Goal Commitment. Implication of the

\section{Study to Policymakers}

When seeking to hire employees who will behave proactively, managers would be wise to select employees who possess a proactive personality. Since employee selection can take time to implement - and is not always an avenue that managers have access to - organizations can also facilitate employee proactive behaviour in their workplaces through the implementation of changes to the situation. Such changes can have an effect even for employees who do not inherently possess proactive personalities. In particular, creating an environment where feedback seeking behavior is encouraged and a climate of goal setting. The study will be of a great importance to policy makers in coming up with strategies and policies geared towards improving the selection of sales people especially during the hiring period as personality traits acts as a prediction of work related attitudes and behaviors.

\section{Managerial Implications}

The findings of this study reveal strong implications for organizational leaders and managers. Managers need to help their sales persons to know the right thing to do in every selling situation through indoor training or programs 
as it helps them feel confident of their ability to perform their sales job well as this increases sales performance. Managers should also ensure that their sales force understand that; their behavior can greatly influence the selling outcome, sales performance is strongly related to the efforts they make, and that every personnel is in a position of fixing what is wrong, hence they can excel at identifying opportunities. Strategies should also be in place to ensure sales personnel strongly feel committed to pursuing their goal and there is much to be gained by trying to achieve it and no situation should stop them from pursuing their desired or set goal. Lastly, managers should set up processes and provisions within their firms that promotes feedback seeking behavior as sales personnel prefer to be told on their overall work performance, how they can improve it, their job performance in comparison to co-workers and would always seek feedback from supervisors about potential advancement within the company.

\section{Limitations and Suggestions for Future study}

Like any other study, this research has several limitations. This study used the cross-sectional design from which it becomes difficult to draw conclusions about the causal relationships among variables. A longitudinal study design is therefore recommended for future researchers as it may provide a more rigorous test of relationships. Lastly, the sample of this study was only limited to Kenyan employees at insurance companies. There might be some culture specific issues which might have been overlooked. Future studies may benefit from an exploration of a wider range of employees at different organizational levels, cultures, and sectors.

\section{References:}

1. Armstrong, G., Kotler, P., Harker, M., \& Brennan, R. (2015). Marketing: an introduction. Pearson Education.

2. Association of Kenya Insurers Report: (2017). Potential Distribution Channels for Insurance Business in Kenya Executive Summary, SBO Research.

3. Asmus S., Florian K., Alwine M. \& Gunther R. (2015).The impact of goal-setting on worker performance-empirical evidence from a realeffort production experiment. Procedia CIRP 26- 127 - 132

4. Bakker, B., Arnold M., Tims \& Daantje, D. (2012). Proactive personality and job performance: The role of job crafting and work engagement. Human relations 65(10), 1359-1378.

5. Bednall, T. C., Sanders, K., \& Runhaar, P. (2014).Stimulating informal learning activities through perceptions of performance appraisal quality and human resource management system strength: A two-wave study. Academy of Management Learning \& Education, 13(1), 45-61. 
6. Bernardin, H. J., \& Wiatrowski, M. (2013). Performance appraisal. Psychology and Policing, 257.

7. Bryman, P. \& Bell, (2007). Personality and organizational behavior. In B. Staw, \& L. L. Cummings (Eds.), Research in organizational behavior, 6 (pp. 1 - 50). Greenwich, CT: JAI Press.

8. Buller, P. F., \& McEvoy, G. M. (2012). Strategy, Human Resource Management and performance: Sharpening line of sight. Human Resource Management Review, 22(1), 43-56.

9. Chiang, C. F., \& Hsieh, T. S. (2012). The impacts of perceived organizational support and psychological empowerment on job performance: The mediating effects of organizational citizenship behavior. International Journal of Hospitality Management, 31(1), 180-190.

10. Comfrey, A.L., \& Lee, H.B (1992). A first course in factor analysis. Hillsdale, NJ: Lawrence Erlbaum Associates.

11. Crant, U. (2000). The volitional benefits of planning. In P. M. Gollwitzer, \& J. A. Bargh (Eds.), the psychology of action: Linking cognition and motivation to behavior (pp. 287-312). New York: Guilford Press.

12. Cronbach, L.J. (1951), "Coefficient alpha and the internal structure of tests, Psychometrika, 6(3), pp. 297-334.

13. Crossley, C. D., Cooper, C. D., \& Wernsing, T. S. (2013). Making things happen through challenging goals: Leader proactivity, trust, and business-unit performance. Journal of Applied Psychology, 98(3), 540.

14. Crowne, G. \& Marlowe, J. (1960). The big five personality dimensions and job performance: A meta-analysis. Personnel Psychology, 44, 126.

15. Dahling, J., O'Malley, A. L., \& Chau, S. L. (2015).Effects of feedback motives on inquiry and performance. Journal of Managerial Psychology, 30(2), 199-215.

16. Day, G. S. (2011). Closing the marketing capabilities gap. Journal of marketing, 75(4), 183-195.

17. De Stobbeleir, K. E., Ashford, S. J., \& Buyens, D. (2011). Selfregulation of creativity at work: The role of feedback-seeking behavior in creative performance. Academy of Management Journal, 54(4), 811-831.

18. Grant, A. M., Gino, F., \& Hofmann, D. A. (2011).Reversing the extraverted leadership advantage: the role of employee proactivity. Academy of Management Journal, 54(3), 528-550.

19. Harrison, C. J., Könings, K. D., Schuwirth, L., Wass, V., \& van der Vleuten, C. (2015).Barriers to the uptake and use of feedback in the 
context of summative assessment. Advances in Health Sciences Education, 20(1), 229-245.

20. Hayes, A.F. \& Scharkow, M. (2013). The relative trustworthiness of inferential tests of the indirect effect in statistical mediation analysis: Does method really matter? Psychological Science 24(10), 19181927.

21. Kammeyer-Mueller, J., Wanberg, C., Rubenstein, A., \& Song, Z. (2013). Support, undermining, and newcomer socialization: Fitting in during the first 90 days. Academy of Management Journal, 56(4), 1104-1124.

22. Kiazad, K., Seibert, S. E., \& Kraimer, M. L. (2014). Psychological contract breach and employee innovation: A conservation of resources perspective. Journal of Occupational and Organizational Psychology, 87(3), 535-556.

23. Klein, H. J., J. C. Molloy, and C. T. Brinsfield. (2012). Reconceptualizing Workplace Commitment to Redress a Stretched Construct: Revisiting Assumptions and Removing Confounds. Academy of Management Review. 37 (1), 130-51.

24. Kruglanski, A. W., Shah, J. Y., Fishbach, A., \& Friedman, R. (2018).A theory of goal systems. In The Motivated Mind (pp. 215258).Routledge.

25. Latham, G. P. \& Pinder, C. C. (2011). Work motivation theory and research at the dawn of the twenty-first century. Annual Review Psychology, 56, 485-516. Latham GP, Yukl GA (1975). Assigned versus participative goal setting with educated and uneducated wood workers. Journal of Applied Psychology; 60(3) 299- 302.

26. Lau, W. K. (2012). The Impacts of Personality Traits and Goal Commitment on Employees' Job Satisfaction. Business \& Economics Journal. BEJ-59. 1-12.

27. Locke, E. A., \& Latham, G. P. (Eds.). (2013). New developments in goal setting and task performance. Routledge.

28. Lord, R. G., Hannah, S. T., \& Jennings, P. L. (2011). A framework for understanding leadership and individual requisite complexity. Organizational Psychology Review, 1(2), 104-127.

29. Ma, C. M., Yu, C.T., and Cheng, B.W (2013). An Integrative Framework among Automobile Salespeople Personality, Learning and Sales Performance, Journal of Applied Sciences, 13(8), 2013, 11771184.

30. Mallin, L., Micheal, Charles B. \& Todd, A. Finkle, (2014).The Proactive Behavior of Younger Salespeople: Antecedents and Outcomes. Journal of Marketing Channels, 21(4). 
31. Martin, K. \& Field, A. (2015). Discovering Statistics Using SPSS, 2nd Ed. SAGE Publications, London.

32. Nunnally, (1978). Self-efficacy as a moderator of information-seeking effectiveness (Working Paper). Dallas, TX: Southern Methodist University.

33. Odunlami, P. (2011). Effect of Sales Promotion as a Tool on Organizational Performance (A case Study of Sunshine Plastic Company), Journal of Emerging Trends in Economics and Management Sciences (JETEMS) 2 (1),9-13.

34. Oh, I. S., Wang, G., \& Mount, M. K. (2011). Validity of observer ratings of the five-factor model of personality traits: a metaanalysis. Journal of Applied Psychology, 96(4), 762.

35. Rust, R.T., T. Ambler, G.S. Carpenter, Kumar, V\& Srivastava, R.K (2014). Measuring Marketing Productivity: Current Knowledge and Future Directions" Journal of Marketing 3(68),76-89

36. Schunk, D. H., \& Zimmerman, B. J. (Eds.). (2012). Motivation and self-regulated learning: Theory, research, and applications. Routledge.

37. Sholihin, M., Pike, R., Mangena, M., \& Li, J. (2011). Goal-setting participation and goal commitment: Examining the mediating roles of procedural fairness and interpersonal trust in a UK financial services organization. The British Accounting Review, 43(2), 135-146.

38. Teece, D., G. Pisano, and Shuen, A. (2015). Dynamic capabilities and strategic management. Strategic Management Journal, 18 (2) 509533.

39. Theodorakis, Y. (1996). The influence of goals, commitment and selfefficacy on motor performance. Journal of Applied Sport Psychology, 8, 171-182.

40. Tolentino, L. R., Garcia, P. R. J. M., Lu, V. N., Restubog, S. L. D., Bordia, P., \& Plewa, C. (2014). Career adaptation: The relation of adaptability to goal orientation, proactive personality, and career optimism. Journal of Vocational Behavior, 84(1), 39-48.

41. Yang, B., Kim, Y., \& McFarland, R. G. (2011). Individual differences and sales performance: A distal-proximal mediation model of selfefficacy, conscientiousness, and extraversion. Journal of Personal Selling \& Sales Management, 31(4), 371-381.

42. Walsh, M. \& Lipinski, J. (2013). The role of the marketing function in small and medium sized enterprises; Journal of Small Business and Enterprise Development 16(4), 569 -585.

43. Woods, S. A., Lievens, F., De Fruyt, F., \& Wille, B. (2013). Personality across working life: The longitudinal and reciprocal 
influences of personality on work. Journal of organizational behavior, 34(S1), S7-S25.

44. Zhang, Z., Wang, M. O., \& Shi, J. (2012). Leader-follower congruence in proactive personality and work outcomes: The mediating role of leader-member exchange. Academy of Management Journal, 55(1), 111-130.

45. Zimmerman, B. J. (2011). Motivational Sources and Outcomes of SelfRegulated Learning and Performance: Graduate Center of City University of New York. In Handbook of Self-Regulation of Learning and Performance (pp. 63-78).Routledge. 